\title{
COVID 19 - its Impact on Packaging Research
}

\author{
Narayan Chandra Saha ${ }^{1}$
}

Published online: 12 November 2020

(c) Indian Institute of Packaging 2020

I take the opportunity to present the twelveth issue of this journal during this challenging time while the world is facing an uncertain situation due to this COVID-19 pandemic which has not only disrupted the normal life but it has also made a great impact on global economic scenario. Interestingly, the packaging industry which is always considered as service industry as these industry have supplied the packaging materials to fast-moving consumer goods (FMCG) industry for essential commodities even during the lockdown stage. Due to this, it is observed that the packaging industry is not much affected due to pandemic as compared to other sectors like travel, tourism, hospitality, automobiles, etc.

Today, the consumers have got a fear of transmission of virus from surface of packaging materials/packages at the beginning of pandemic which has made the consumers to become more conscious about health, hygiene and safety. But this has eventually created more research opportunity for the application of smart and intelligent packaging in the form of sensor based of identification technique to ensure about "Virus-free" packages which might cause health hazards. At the same time, the demand for "take away food" is increased substantially which has led to further research opportunity for the application of modified atmosphere packaging technique (MAP) with increased shelf life for "ready-to-eat-food" products as there is an increased of demand for packaged foods as the consumers do not prefer to visit to the restaurants for "Sit- down" meals. Hence, this changed scenario of life style and consumer's preferences due to COVID-19 pandemic has created a great opportunity for packaging research.

At the same time, the packaging industries are also gearing-up themselves to adopt new business strategies to focus towards the use of innovative technology with more automation at every level of manufacturing process to maintain the existing scale of production with minimum work force by meeting the compliance of the safety protocols like social distancing.

Under this background, I feel happy to present the third issue of fourth year (volume 4, number 3) of the Journal of Packaging Technology and Research (JPAC) which is an international peer-reviewed publication that publishes original, high-quality research papers on topics related to packaging Science and Technology.

This journal aims at publishing inter-disciplinary approaches to global issues related to packaging like development of innovative environmentally friendly packaging materials to meet the requirements of environmental regulations related to packaging.

The current issue has covered five important articles: Design Modification of Ice-Cream Cone to Control Ink Migration and Crimping, Effect of Stretch Wrap Parameters on the Transmissibility of Unitized Loads Excited by Random Vibration, Nanocellulose, its applications, consequences and challenges in papermaking, Evaluation of Polymethyl Methacrylate Sheets as a RadiationShielding Material, Development of Essential Oil-Incorporated Active Film Based on Biodegradable Blends of Poly(Lactide)/Poly(Butylene Adipate-co-Terephthalate) for

Narayan Chandra Saha drsaha59@gmail.com

1 Indian Institute of Packaging, Mumbai, India 
Food Packaging application which are contributed by the researchers of the reputed Research Institutions and Universities of India and overseas.

It is expected that the published research papers in this issue of the journal will be highly useful for the researchers who are involved in basic as well as applied research in the field of packaging.

Finally, may I invite all the researchers to submit their research papers, review papers, case studies for double-blind international peer review. The peer-reviewed research paper will be made available for the benefit of researchers.
To submit online or to read papers published, please visit the journal webpage at https://w.w.w.springer.com/engin eering/industrial+management/journal/41783.

N. C. Saha,

Editor-in-Chief.

Publisher's Note Springer Nature remains neutral with regard to jurisdictional claims in published maps and institutional affiliations. 